\title{
PMB Drug Company Contact
}

National Cancer Institute

\section{Source}

National Cancer Institute. PMB Drug Company Contact. NCI Thesaurus. Code C51843.

The drug company employee who is authorized to serve as a primary contact between the company and NCI CTEP Pharmaceutical Management Branch (PMB) regarding pharmaceutical issues (drug acquisition, quality, supply, inventory management, distribution, etc.) pertaining to the investigational agent utilized in the $\mathrm{NCl}$-sponsored clinical trial. 